\title{
HEARING AND ECHOLOCATION IN THE AUSTRALIAN GREY SWIFTLET, COLLOCALIA SPODIOPYGIA
}

\author{
BY ROGER B. COLES \\ Zoologisches Institut, Universität München, Luisenstrasse 14, 8 München 2, \\ West Germany \\ MASAKAZU KONISHI \\ Division of Biology, California Institute of Technology, Pasadena, CA 91125, USA \\ AND JOHN D. PETTIGREW \\ Department of Physiology $\Xi$ Pharmacology, University of Queensland, St Lucia, \\ Queensland 4067, Australia \\ Accepted 3 February 1987

\begin{abstract}
S UMMARY
The frequency sensitivity of hearing in the grey swiftlet, Collocalia spodiopygia, was determined by neuronal recordings from the auditory midbrain (MLD). The most sensitive best frequency response thresholds occurred between 0.8 and $4.7 \mathrm{kHz}$, with the upper frequency limit near $6 \mathrm{kHz}$. Spectral analysis of echolocation click pairs revealed energy peaks between 3.0 and $8.0 \mathrm{kHz}$ for the foreclick, compared to $4 \cdot 0-6 \cdot 0 \mathrm{kHz}$ for the principal click. The relationship between good hearing sensitivity and click energy peaks in the swiftlet extends about an octave higher than it does in the oilbird (Steatornis caripensis).
\end{abstract}

\section{INTRODUCTION}

Echolocation is known to occur in only two families of birds. The Steatornithidae is represented by one species, the oilbird (Steatornis caripensis), which is known to echolocate and is a nocturnal frugivore from South America (Griffin, 1953; Konishi \& Knudsen, 1979; Suthers \& Hector, 1985). In the Apodidae a number of swiftlet species (Collocalia spp.) are also known to echolocate and are diurnal insectivores (Novick, 1959; Medway, 1959). Swiftlets are common to south-east Asia (Medway, 1962) including the north-east regions of Australia (Smyth, Pecotich \& Roberts, 1980). Although the oilbird and echolocating swiftlets have contrasting life-styles, they both use echolocation solely for navigation in the dark caves where they roost and nest. Detailed study of the echolocation system of these birds has been limited since they inhabit fairly remote neo- and palaeotropical regions. Usually such studies have been restricted to the recording of echolocation clicks (Griffin, 1953; Medway, 1959; Novick, 1959; Medway \& Pye, 1977; Fenton, 1975; Hollander, 1971; Konishi \& Knudsen, 1979; Smyth, 1979) and determining target resolution by obstacle Key words: swiftlet, hearing, echolocation click, midbrain. 
avoidance during echolocation (Griffin \& Suthers, 1970; Fenton, 1975; Konishi \& Knudsen, 1979; Griffin \& Thompson, 1982; Thompson \& Suthers, 1983). Detailed analyses of the click production mechanism have been reported recently for the swiftlet and oilbird (Suthers \& Hector, 1982, 1985).

To understand the adaptations for echolocation in birds, it is necessary to examine the auditory system as well as the vocal system. To date the only published data concerning auditory sensitivity in echolocating birds has been reported in the oilbird and was based on the frequency sensitivity of forebrain-evoked potentials (field L) and cochlear potentials (Konishi \& Knudsen, 1979). This paper reports the first recordings from auditory neurones in an echolocating bird, the grey swiftlet (Collocalia spodiopygia), made in order to determine the frequency sensitivity of the auditory system. These results are compared with an analysis of the energy spectra of echolocating clicks to establish the emitter-receiver relationship.

\section{MATERIALS AND METHODS}

Grey swiftlets (average mass $10 \mathrm{~g}$ ) were mist-netted at the cave entrance of a large colony in a limestone karst near Chillagoe in North Queensland, Australia. For physiological recordings, the birds were brought immediately to a temporary laboratory (a motel room) in the nearby town. Swiftlets were anaesthetized with a combination of ketamine $\left(20 \mathrm{mg} \mathrm{kg}^{-1}\right)$ and rompun $\left(1 \mathrm{mg} \mathrm{kg}^{-1}\right)$ and the responses of single neurones from the midbrain auditory nucleus (MLD) were recorded by tungsten-in-glass microelectrodes using conventional extracellular techniques. Each bird was placed in an elevated position facing a $10 \mathrm{~cm}$ diameter speaker (Pioneer TS$162 \mathrm{DX}$ ) at a distance of $34 \mathrm{~cm}$. Sound pressures at the position of the bird's head were recorded with a $1.3 \mathrm{~cm}$ Bruel \& Kjaer microphone (type 4133 ) by measuring the output voltage of the microphone on an oscilloscope screen or by using a portable digital voltmeter. The free field sound pressure level (SPL) re. $20 \mu \mathrm{Pa}$ was calculated in decibels $(\mathrm{dB})$ with reference to the calibrated sensitivity of the microphone. Acoustical stimuli were repetitive tone bursts in the frequency range $0 \cdot 2-8 \mathrm{kHz}$ with $2 \mathrm{~ms}$ rise/fall time and $20 \mathrm{~ms}$ plateau duration. The birds were heated from below with a hot water heater and the air temperature close to the bird's head was maintained between $29^{\circ}$ and $33^{\circ} \mathrm{C}$.

Sound recordings of echolocation clicks were obtained from a tethered bird attempting to fly in a small, dark, sound-absorbing chamber (approximately $1.5 \mathrm{~m}$ in diameter) made from fibreglass insulation batts. The recording chamber was situated in the town hall, to provide a quiet environment. A microphone (Sennheiser Model MKE 401) was inserted into the chamber from the side so that a constant recording distance of $34 \mathrm{~cm}$ from the bird was achieved. Under these conditions, click sequences with uniform amplitude were emitted by the bird and recorded on a portable tape recorder (Uher CR240). The recorded clicks were relatively free from interference by background noise and echoes (Figs 1,3), in contrast to field recordings in caves, for example. 

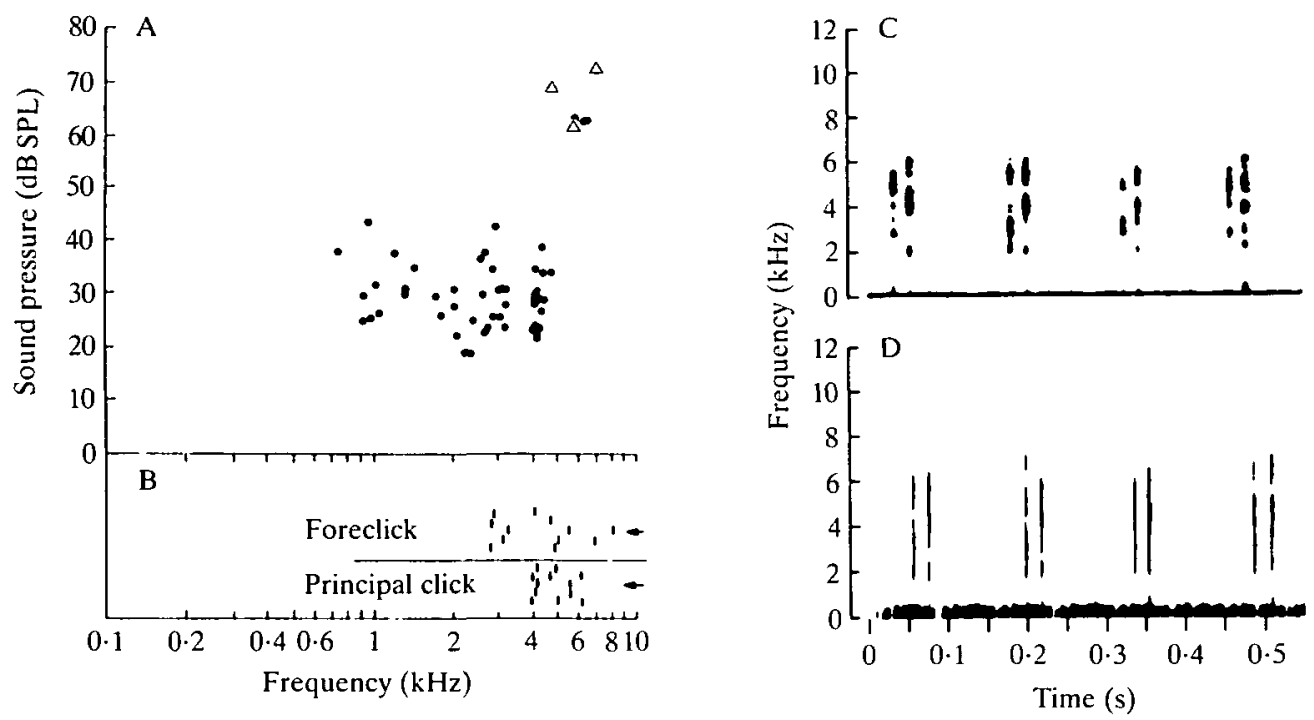

Fig. 1. (A) Distribution of best frequency thresholds for 56 auditory neurones (circles) from the midbrain (MLD) of a grey swiftlet (Collocalia spodiopygia). Open triangles are data from unit clusters. (B) Distribution of energy peaks for five consecutive echolocation clicks of $C$. spodiopygia. Foreclicks and principal clicks (for definition see text) analysed individually by the fast Fourier transform (FFT) method (see Fig. 3). Horizontal arrows indicate spectral peaks derived from the click pair shown in Fig. 3. (C) Narrowband $(45 \mathrm{~Hz})$ and $(D)$ wideband $(300 \mathrm{~Hz})$ sonagraphic analysis of echolocation clicks of $C$. spodiopygia. Note the paired click structure (as shown in Fig. 3, inset).

\section{RESULTS AND DISCUSSION}

Recordings were made from 121 auditory neurones from 19 separate electrode penetrations through the MLD in five birds. The MLD is a major afferent relay nucleus and to determine the frequency sensitivity of the auditory system the best frequency $(\mathrm{BF})$, defined by the most sensitive excitation threshold, was obtained for each neurone. Response thresholds were judged subjectively, relative to spontaneous discharge levels, by listening to the amplified neural activity through headphones. An example of the BF threshold distribution for 56 units recorded in one bird is shown in Fig. $1 \mathrm{~A}$ and indicates that most units with thresholds between 18 and $45 \mathrm{~dB}$ SPL have BFs ranging from about $0.8 \mathrm{kHz}$ up to $4.7 \mathrm{kHz}$. A few units were recorded with low BFs near $250 \mathrm{~Hz}$, and occasionally it was possible to find units and unit clusters tuned to high frequencies around $6-7 \mathrm{kHz}$ (Fig. 2) but thresholds were high i.e. at or above $70 \mathrm{~dB}$ SPL. The room acoustics, especially background noise and the difficulty of free field calibration, probably account for the minimum thresholds being about $18 \mathrm{dBSPL}$, but these were the most sensitive estimates possible under 'field' conditions. Pooled BF data for all the birds studied are shown in Fig. 2 as a histogram of BFs at one-quarter octave intervals. Unit BFs most frequently occurred between 2 and $5 \mathrm{kHz}$, with some clustering of units around the $4-4.8 \mathrm{kHz}$ band. 


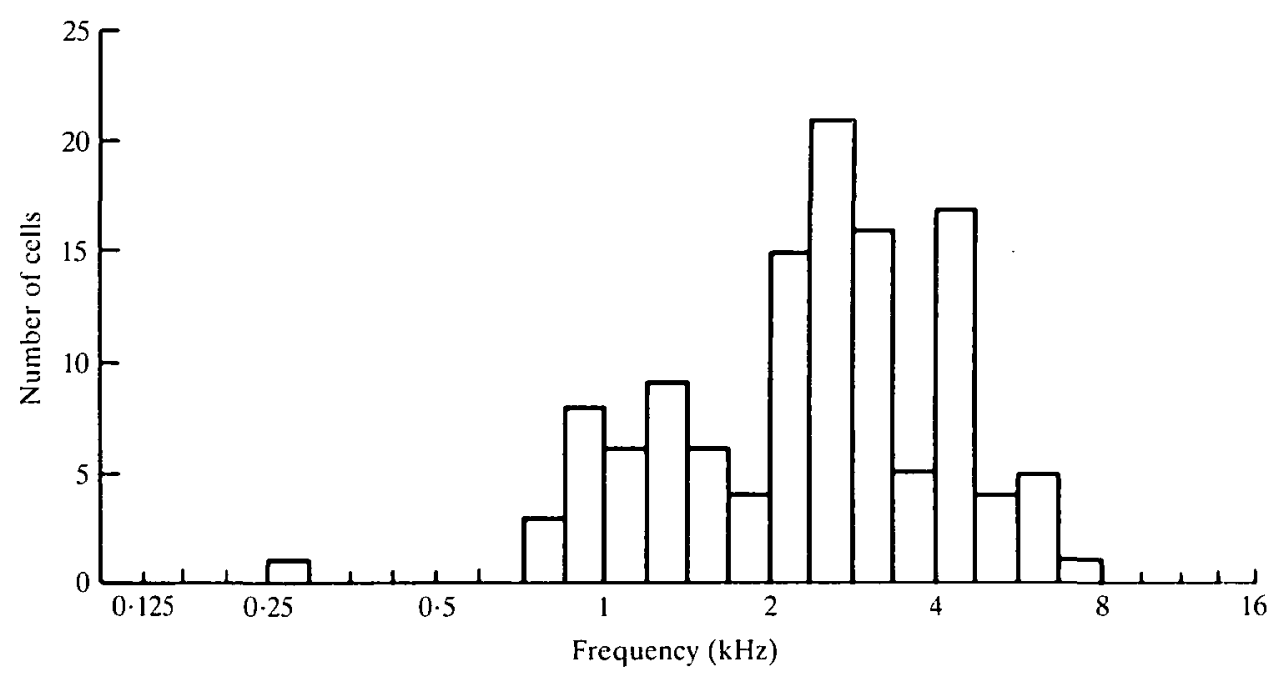

Fig. 2. Distribution of best frequencies for a sample of 121 neurones recorded from the midbrain of Collocalia spodiopygia. Class interval is one-quarter octave.

The most sensitive auditory units in the grey swiftlet's midbrain prefer frequencies between about 2 and $4.5 \mathrm{kHz}$ and despite the small number of swiftlets studied, it is unlikely that a population of high-frequency neurones was missed. Electrode tracks were made throughout the rostrocaudal and mediolateral MLD, and electrode penetrations traversed the full vertical extent of the nucleus. Typically these penetrations showed a strict tonotopic sequence progressing from low to high $\mathrm{BF}$ as the electrode was advanced dorsoventrally, similar to observations in other avian species (Knudsen \& Konishi, 1978; Coles, 1980). An interesting result from the present study is the limited extent of high-frequency sensitivity, as very few units have BFs above about $4.8 \mathrm{kHz}$. Apparently the grey swiftlet does not develop its high-frequency sensitivity to the same extent as similarly sized songbirds (Konishi, 1970) or acoustically specialized birds such as owls (Knudsen \& Konishi, 1978). Frequency sensitivity in the grey swiftlet resembles more closely that in the pigeon and domestic fowl, for example (Sachs, Young \& Lewis, 1974; Coles \& Aitkin, 1979). Unpublished data on the frequency sensitivity of cochlear microphonic potentials in the echolocating swiftlet Collocalia fuciphaga are difficult to compare to present data due to extreme variability in the results and the lack of absolute thresholds (Hollander, 1971). However, there is some indication that the maximum sensitivity to sound in both $C$. fuciphaga and $C$. esculenta lies between 1 and $4 \mathrm{kHz}$ with a marked reduction in sensitivity for higher frequencies (Hollander, 1971), and these data are supported by the present observations in $C$. spodiopygia. Thus it is possible to conclude tentatively that echolocating swiftlets extend their frequency sensitivity up to $4 \cdot 0-5 \cdot 0 \mathrm{kHz}$, which is significantly higher than the oilbird, in which auditory sensitivity diminishes rapidly above $2 \cdot 0-2 \cdot 5 \mathrm{kHz}$ (Konishi \& Knudsen, 1979).

Echolocating pulses used by swiftlets are click-like signals (Medway, 1959; Novick, 1959; Griffin \& Suthers, 1970; Hollander, 1971; Fenton, 1975; Medway \& Pye, 1977; Smyth, 1979), which have been recorded from individual grey swiftlets 
under controlled conditions (see Materials and Methods). Sonagraphic analysis of echolocation clicks (Fig. 1C,D) reveals a paired structure with a constant interval of about $18 \mathrm{~ms}$ between the first (foreclick) and second (principal) click (as defined by Hollander, 1971). During echolocation, the interval between click pairs varies depending on the proximity of an object and maximum rates of about $25 \mathrm{~s}^{-1}$ occur when swiftlets approach the nest. The narrow band analysis in Fig. 1C indicates a discontinuous energy spectrum with variable peaks between 3.5 and $5.5 \mathrm{kHz}$, both within and between click pairs. A digitized click pair shown in Fig. 3 (inset) indicates that the peak amplitude of the principal click has a duration of about $1.5 \mathrm{~ms}$, with a total waveform duration of up to $5 \mathrm{~ms}$. The energy spectra of digitized click trains were computed by an FFT algorithm (PDP 11/03) for each component in a click pair and for several successive pairs. Individual spectra for a typical click pair are shown in Fig. 3A,B, confirming that both the foreclick and the principal click have two or three major energy peaks with relatively little energy above $6 \mathrm{kHz}$, as suggested in Fig. 1C. In Fig. 3A the energy peaks for the foreclick occur at $3.3 \mathrm{kHz}$ and $5.5 \mathrm{kHz}$, compared to $4 \cdot 1 \mathrm{kHz}$ and $5 \cdot 5 \mathrm{kHz}$ for the principal click (Fig. 3B). Consistent lowfrequency peaks in the energy spectra were seen between 0.2 and $0.5 \mathrm{kHz}$ but these are unlikely to be part of the echolocation process, and may be due to background

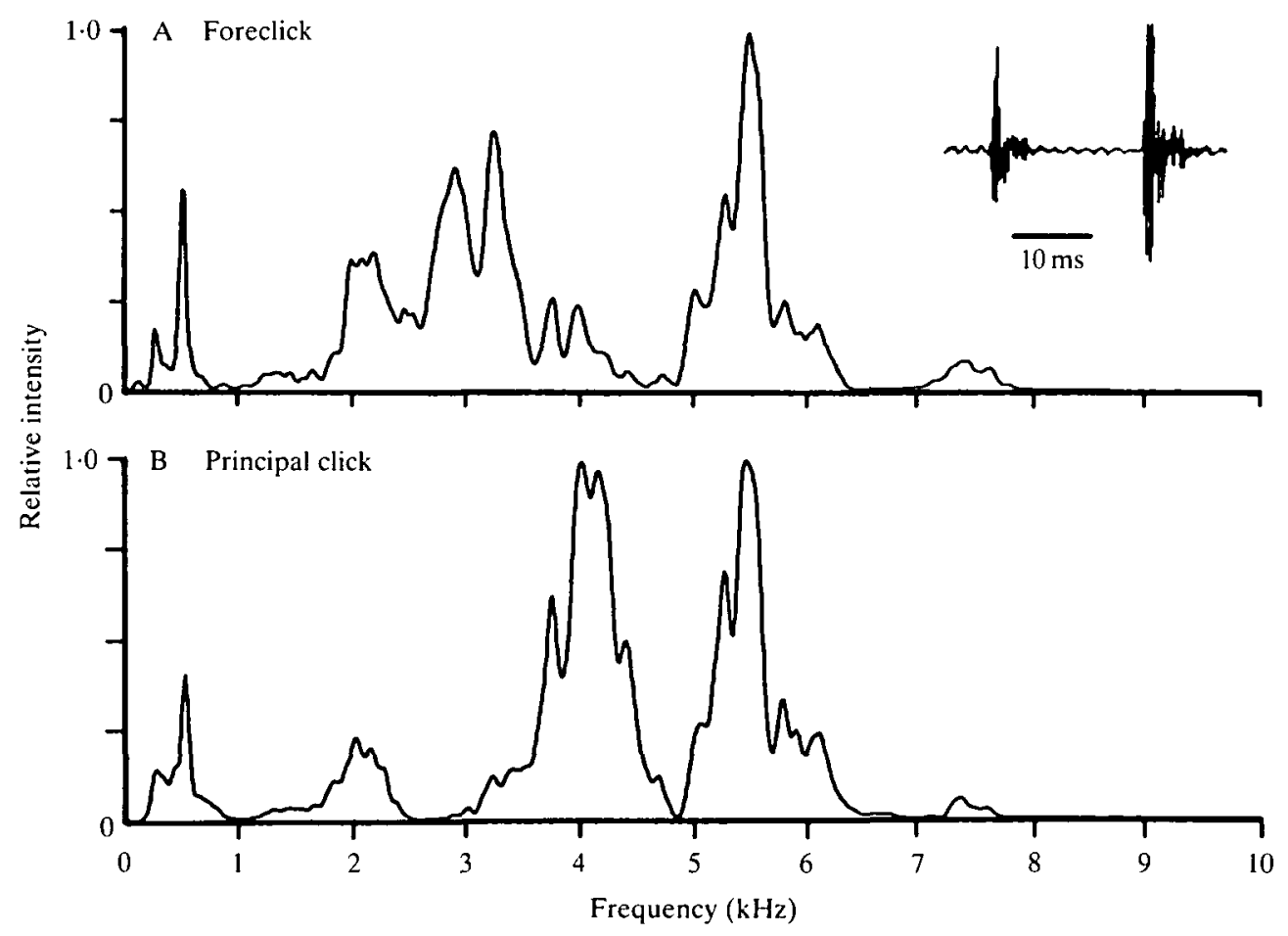

Fig. 3. (A,B) Energy spectra for the foreclick and principal click of an echolocation pulse of Collocalia spodiopygia based on fast Fourier transform (FFT) analysis. Inset: digitized waveforms of an echolocation click pair. Foreclick precedes the principal click which is larger in amplitude. 
noise in the recordings generated by wing flapping (see Fig. 3, inset). The energy peaks of five consecutive click pairs are summarized in Fig. 1B and, despite some variability in the energy for both click components, the principal click energy peaks are more consistent than for the foreclicks. The principal click energy peaks occur in a band between 4.0 and $6.0 \mathrm{kHz}$ compared to a $3.0-8.0 \mathrm{kHz}$ energy band for the foreclick. Based on the limited number of pairs examined here, most of the click train energy in C. spodiopygia is restricted to a band between 4.0 and $5.5 \mathrm{kHz}$. The extent to which swiftlets use echo information generated by either the first or second component of each click pair is unknown, but the second component (principal click) maybe more important since it always has the greater amplitude (see Fig. 3, inset). Nevertheless, it has been suggested that there may be some advantage in the use of pulse pairs for echolocation (Buchler \& Mitz, 1980).

In comparison with the frequency sensitivity of the auditory midbrain (Fig. 1A), the grey swiftlet uses echolocation clicks with energy bands that fall mainly just within the upper frequency regions of good sensitivity to sound (Fig. 1B). This highfrequency bias in the swiftlet appears to be more marked than the relationship between emitter and receiver recently shown for the oilbird, which coincide around $1 \cdot 5-2 \cdot 5 \mathrm{kHz}$ (Konishi \& Knudsen, 1979). Presumably swiftlets make use of the highest energy peaks in the clicks to get the best target resolution, but since clicks are broadband, lower frequencies could also be used. Preferential use of the energy band between 4.0 and $5.5 \mathrm{kHz}$ cannot be stated categorically, and a much more exhaustive analysis of click trains, the auditory system and behavioural performance is required. The unit data in this study suggest that the most frequent $\mathrm{BFs}$ occur in the regions of click energy peaks and the apparent clustering of units near $4 \cdot 0-4.5 \mathrm{kHz}$ is particularly interesting. However, any such tendency must be confirmed by further detailed mapping of the MLD. An over-representation of the major frequency band for sonar (click) energy could conceivably occur in the auditory system of echolocating swiftlets as in echolocating bats. The volume of the midbrain torus is about $100 \%$ larger in Collocalia fugiphaga, an echolocator, than in C. esculenta, a non-echolocator, but it is unclear whether it is the auditory nucleus (MLD) per se which is hypertrophied (Hollander, 1971).

In summary, the click energy in swiftlets is significantly higher than in the oilbird. This difference is also reflected in the receiver-emitter match, since the auditory sensitivity in the oilbird is best around $2 \mathrm{kHz}$ (Konishi \& Knudsen, 1979) compared to $C$. spodiopygia where the frequency sensitivity extends about an octave higher to $4.5 \mathrm{kHz}$. Given the much larger size of the oilbird (400 g; Snow, 1961) compared to swiftlets $(10 \mathrm{~g})$ this may be useful, since swiftlets are able to fly through smaller gaps.

The nest is an acoustic target of major interest to the swiftlet during echolocation. It is a small bracket-shaped structure glued to the cave wall and has an average diameter of about $7 \mathrm{~cm}$. These dimensions correspond closely to the sound wavelengths used during echolocation but it is not known whether the swiftlet nest has any special properties for echo reflection. In comparison, the oilbird nest is much larger with a diameter up to $38 \mathrm{~cm}$ (Snow, 1961) and may be designed for an echolocation system with longer wavelengths. 
This work was completed as part of the 1980 Biosonar Expedition to Chillagoe, Australia. We gratefully acknowledge funding by the NSF (grant no. BNS-79. 13968), the assistance of members of the Chillagoe Caving Club, Queensland National Parks and Wildlife Service, and many other individuals whose help was indispensable to the success of the expedition.

\section{REFEREN CES}

Buchler, E. R. \& MrTz, A. R. (1980). Similarities in design features of orientation sounds used by simpler, nonaquatic echolocators. In Animal Sonar Systems (ed. R. G. Busnel \& J. F. Fish), pp. 871-874. New York: Plenum Press.

Coles, R. B. (1980). Functional organization of auditory centres in the midbrain of birds. Int. Omithol. Congress XVII Berlin, 714-717.

Coles, R. B. \& AITKIN, L. M. (1979). The response properties of auditory neurons in the midbrain of the domestic fowl (Gallus gallus) to monaural and binaural stimuli. 7 . comp. Physiol. 134, 241-251.

FEnTON, M. B. (1975). Acuity of echolocation in Collocalia hinundinacea (Aves: Apodidae), with comments on the distribution of echolocating swiftlets and molossid bats. Biotropica 7, 1-7.

Griffin, D. R. (1953). Acoustic orientation in the oilbird, Steatomis. Proc. natn. Acad. Sci. U.S.A. 39, 884-893.

Griffin, D. R. \& Suthers, R. A. (1970). Sensitivity of echolocation in cave swiftlets. Biol. Bull. mar. biol. Lab., Woods Hole 139, 495-501.

Griffin, D. R. \& Thompson, D. (1982). Echolocation by cave swiftlets. Behav. Ecol. Sociobiol. $10,119-123$.

Hollander, P. (1971). Adaptations for echolocation in cave swiftlets (Collocalia). Ph.D. thesis, Yale University.

KNUDSEN, E. I. \& Konishi, M. (1978). Space and frequency are represented separately in the auditory midbrain of the owl. $\mathcal{F}$. Neurophysiol. $41,870-884$.

Konishi, M. (1970). Comparative neurophysiological studies of hearing and vocalizations in songbirds. Z. vergl. Physiol. 66, 257-272.

Konishi, M. \& KNudsen, E. I. (1979). The oilbird: hearing and echolocation. Science 204, 425-427.

MedWAY, LoRd (1959). Echolocation among Collocalia. Nature, Lond. 184, 1352-1353.

Medway, LoRd (1962). The swiftlets (Collocalia) of Niah Cave, Sarawak. Ibis 104, 45-66.

MEDWAY, LORD \& PYE, J. D. (1977). Echolocation and the systematics of swiftlets. In Evolutionary Ecology (ed. B. Stonehouse \& C. Perrins), pp. 225-238. London: Macmillan.

Novick, A. (1959). Acoustic orientation in the cave swiftlet. Biol. Bull. mar. biol. Lab., Woods Hole 117, 497-503.

Sachs, M. B., Young, E. D. \& LewIS, R. H. (1974). Discharge patterns of single fibres in the pigeon auditory nerve. Brain Res. 70, 431-447.

SмYтн, D. M. (1979). Studies of echolocation in the grey swiftlet, Aerodramus spodiopygius. Ph. D. thesis, James Cook University.

Sмyтh, D. M., Pecotich, L. \& Roberts, J. R. (1980). Notes on the distribution and breeding of the grey swiftlet, Aerodramus spodiopygius. Sunbird 11, 1-19.

SNow, D. W. (1961). The natural history of the oilbird, Steatomis caripensis, in Trinidad, W.I. I. General behaviour and breeding habits. Zoologica 46, 27-48.

Suthers, R. A. \& Hector, D. H. (1982). Mechanism for the production of echolocating clicks by the grey swiftlet Collocalia spodiopygia. F. comp. Physiol. 148, 457-470.

Suthers, R. A. \& Hector, D. H. (1985). The physiology of vocalization by the echolocating oilbird, Steatomis caripensis. F. comp. Physiol. 156, 243-266.

Thompson, D. B. \& Suthers, R. A. (1983). Acuity of echolocation in the oilbird, Steatomis caripensis. F. acoust. Soc. Am. 74, S32. 
